\title{
Weight-Loss Diet Alone or Combined with Progressive Resistance Training Induces Changes in Association between the Cardiometabolic Risk Profile and Abdominal Fat Depots
}

\author{
Marisol García-Unciti ${ }^{a}$ Mikel Izquierdo ${ }^{b}$ Fernando Idoate ${ }^{c}$ \\ Esteban Gorostiaga $^{b}$ Ana Grijalba ${ }^{d}$ Francisco Ortega-Delgado ${ }^{f}$ \\ Cristina Martínez-Labari ${ }^{b}$ José M. Moreno-Navarrete ${ }^{f}$ Lluis Forga ${ }^{e}$ \\ José Manuel Fernández-Real ${ }^{f}$ Javier Ibáñez $^{\mathrm{b}}$

\begin{abstract}
a Department of Nutrition and Food Sciences, Physiology and Toxicology, University of Navarra, ${ }^{\mathrm{b}}$ Studies, Research and Sports Medicine Center, Government of Navarra, 'Department of Radiology, Clínica San Miguel, and Departments of ${ }^{\mathrm{d}}$ Clinical Biochemistry and ${ }^{\mathrm{e}}$ Endocrinology, Hospital of Navarra, Pamplona, and ${ }^{\mathrm{f}}$ Department of Diabetes, Endocrinology and Nutrition, Institut d'Investigació Biomédica de Girona (IdIBGi), CIBER Fisiopatología de la Obesidad y Nutrición CB06/03/010, Girona, Spain
\end{abstract}

\section{Key Words}

Hypocaloric diet · Strength training • Insulin resistance •

Lipid profile $\cdot$ Visceral adipose tissue $\cdot$ Subcutaneous

adipose tissue $\cdot$ Midthigh fat $\cdot$ Adipocytokines

\begin{abstract}
Background/Aims: A weight-loss diet alone or combined with a progressive resistance training program induced different adaptations on cardiometabolic risk, i.e. regional changes in visceral adipose tissue (VAT) and subcutaneous adipose tissue (SAT) volume distribution patterns. We hypothesized that a heterogeneous adipose tissue metabolism may exist between visceral fat at different discal levels. Methods: Thirty-four obese women, aged 40-60 years, were randomized to three groups: a control group $(n=9)$, a diet group ( $\mathrm{WL} ; \mathrm{n}=12$ ) with a caloric restriction of $500 \mathrm{kcal} /$ day during 16 weeks, or a diet-plus-resistance-training group $(\mathrm{WL}+\mathrm{RT} ; \mathrm{n}=13)$ with the same caloric restriction and a 16week resistance training of 2 sessions per week. Results: The
\end{abstract}

association pattern between abdominal fat depots and glucose metabolism variables showed a change from the L4-L5 region (preintervention) to VAT L2-L3 and SAT L2-L3 in the WL and WL+RT groups, respectively. It is noteworthy that accumulation of fat in the midthigh was not characterized by a more favorable lipid profile or glucose metabolism. Conclusion: Our results reinforce the importance of considering L2-L3 images to predict insulin resistance after a weight-loss diet, alone or combined with resistance training.

Copyright $\odot 2012$ S. Karger AG, Basel

\section{Introduction}

Cardiovascular disease represents the most serious, neglected health problem for women in the world $[1,2]$. Current evidence supports that obesity increases the risk of cardiovascular disease and other chronic diseases such as diabetes [3, 4]. The development of obesity-related complications depends on the amount and distribution

\section{KARGER}

Fax +4161306 1234

E-Mail karger@karger.ch

www.karger.com
(C) 2012 S. Karger AG, Basel

0250-6807/12/0614-0296\$38.00/0

Accessible online at:

www.karger.com/anm
Dr. Javier Ibáñez

Centro de Estudios, Investigación y Medicina del Deporte

C/ Sangüesa 34

ES-31005 Pamplona (Spain)

E-Mail jibanezs@navarra.es 
of body fat and its endocrine function [5]. It is generally assumed that different cytokines produced by the adipose tissue are the link between obesity and obesity-related complications [5]. Nevertheless, most of the data regarding obesity and the risk of cardiometabolic disease have been derived from experimental protocols involving cross-sectional $[3,4]$ or prospective studies using surrogate markers of abdominal obesity such as waist circumference $[6,7]$ or the waist-to-hip ratio (WHR) $[8,9]$. Magnetic resonance imaging (MRI) is a well-established validated method for the estimation of compartmental adipose tissue with a multiple-image approach $[10,11]$, and could be useful for clinicians to determine which women are at cardiometabolic risk through a cheaper and easier single-image approach.

Although the L4-L5 image is often chosen to estimate total visceral adipose tissue (VAT) and subcutaneous adipose tissue (SAT) volumes, controversy still exists about the ideal anatomical region for quantifying abdominal adipose tissue or for predicting obesity-related cardiometabolic risk by computed tomography [12] or MRI [13]. In this context, prospective cohort trials using an imaging procedure to estimate fat depots and their relationship with different metabolic variables (e.g. IL-6 and TNF- $\alpha$ ) reflecting cardiometabolic risk need to be further examined.

Lifestyle behaviors are the cornerstone of cardiometabolic disease prevention [14-16]. Lifestyle changes such as weight loss and regular physical activity are recognized as effective nonpharmacological interventions with beneficial effects on cardiovascular and metabolic risk [14-16]. In this context, it is known that in obese women progressive resistance training (PRT) leads to significant visceral fat decreases [16, 17], improving the cardiometabolic risk profile [17].

In our earlier studies we showed that a weight-loss diet alone or combined with a PRT program induced different adaptations on glucose metabolism and lipid profile variables [17], as well as different regional changes in VAT and SAT volume distribution patterns [18]. The aims of this study were to determine the relationships between the adipose tissue depots in different abdominal discal levels and cardiometabolic risk factors in perimenopausal obese women. We hypothesized that a weight-loss diet alone or combined with a PRT program could highlight a heterogeneous adipose tissue metabolism at different discal levels of visceral fat, in parallel with the observed different regional changes in fat volume distribution patterns.

Weight Loss and Cardiometabolic Risk Factors

\section{Material and Methods}

\section{Subjects}

Thirty-four sedentary, nonsmoking, obese (BMI 30-40 kg. $\mathrm{m}^{-2}$ ) women, aged 40-60 years, were recruited through an advertisement in a local newspaper. Before inclusion into the study, all candidates were thoroughly screened using an extensive medical history, resting and maximal exercise electrocardiogram, and blood pressure measurement. Cardiovascular, neuromuscular, arthritic, pulmonary, or other debilitating diseases as determined by one or all of the screening tools were reasons for exclusion from the study. None of the subjects received any medication, also not associated with menopause. All of the subjects were informed in detail about the possible risks and benefits of the project, and they then signed a written consent form before participating in the study. This project was approved by the ethical committee of the regional Health Department. Participants were assigned to one of three groups: a control group $(n=9)$, a diet group (WL; $n=12)$ with a caloric restriction of $500 \mathrm{kcal} / \mathrm{day}$, or a diet-plus-resistance-training group $(\mathrm{WL}+\mathrm{RT} ; \mathrm{n}=13)$ with the same caloric restriction as the WL group and a 16-week supervised whole-body resistance training program of 2 sessions per week. The different ovarian functional status of women was avoided by measuring basal circulating estradiol levels (tables 1,2) and balancing menopausal and perimenopausal women between groups at the beginning of the study. The subjects were tested on two different occasions, i.e. a few days before the beginning of the training program and/or diet and 72-96 h after the end of the study, using identical protocols. During the 16 weeks of the study the subjects maintained their customary recreational physical activities (e.g. walking). The baseline characteristics of the subjects are presented in table 1.

\section{Anthropometric Variables}

The height of barefoot subjects was measured to the nearest 0.1 $\mathrm{cm}$. Body mass was measured on the same standard medical scale to an accuracy of $\pm 100 \mathrm{~g}$. Waist and hip circumferences were measured with the subject standing erect with arms at the sides and feet together, wearing only underwear. The measurer placed an inelastic tape around the subject, without compressing the skin, on a horizontal plane at the level of the last false rib and the buttocks, respectively. The measurement was recorded to the nearest $0.1 \mathrm{~cm}$.

\section{Magnetic Resonance Imaging}

The volumes of VAT and SAT (abdominal and thigh) and muscle volume in the thigh were measured by magnetic resonance. MRI was performed with a 1T magnet (Magnetom Impact Expert; Siemens) using a body coil. The subjects were examined in a supine position with both arms positioned parallel along the sides of the body. We obtained a spoiled T1-weighted gradient-echo sequence with a repetition time of $127 \mathrm{~ms}$ and an echo time of $6 \mathrm{~ms}$. Each half body volume was scanned using two stacks, each containing 10 contiguous 10 -mm-thick slices. The discal level analysis was conducted labeling each image referred to discal spaces using sagittal scout images. Each stack was acquired in $20 \mathrm{~s}$ and an interleaved slice order was used. An FOV of $500 \mathrm{~mm}$ was used and all the stacks were acquired with breath holding. The total investigation time was about $5 \mathrm{~min}$.

MRI of both thighs was then obtained. A T1-weighted sequence was used with a repetition time of $645 \mathrm{~ms}$ and a spin echo 
Table 1. Descriptive characteristics of subjects at baseline

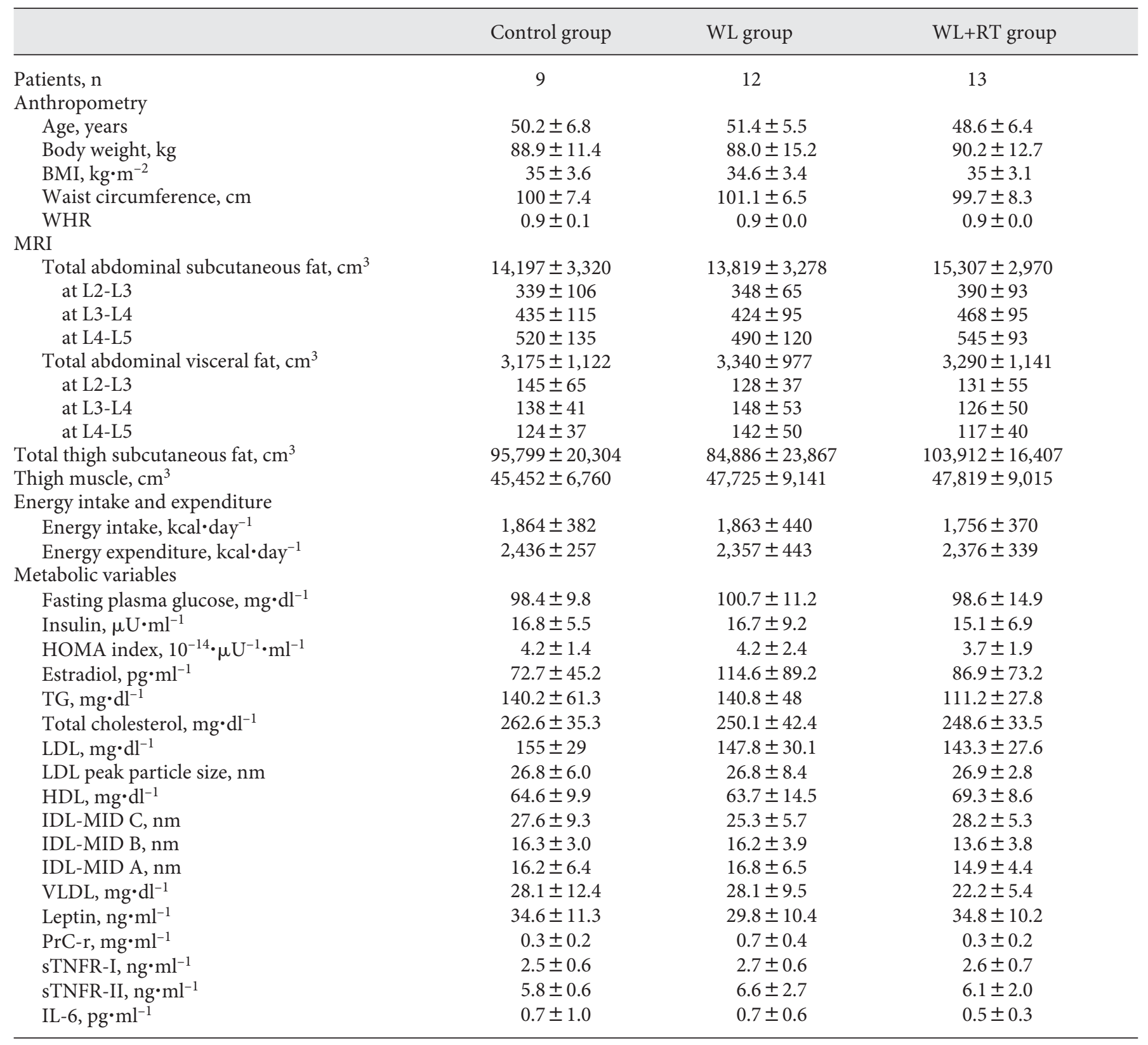

Values are expressed as means $\pm \mathrm{SD}$.

time of $20 \mathrm{~ms}$. The field of view was $500 \times 500 \mathrm{~mm}$ and the matrix was $512 \times 192$. The slices were $10 \mathrm{~mm}$ thick, with no gap between the slices. The thighs were scanned using two stacks, each containing 15 contiguous 10 -mm-thick slices; the scan was performed axially from the articular boundary of the lowest external femoral condyle. The images were retrieved from the scanner according to a DICOM (Digital Imaging and Communications in Medicine) protocol. The acquired axial MR images were transferred to an external personal computer running Windows XP.
The level of each abdominal image was labeled using sagittal scout images, referred to the discal level. We used specially designed image analysis software (SliceOmatic 4.3; Tomovision Inc., Montreal, Que., Canada) for quantitative analysis of the images. Calculations of adipose tissue were carried out by the same investigator. The intra-observer reliability for calculation of the total VAT, SAT, and TAT volumes was 0.99 with a coefficient of variation (CV) of $5-8 \%$. 
Table 2. Changes between baseline and posttraining in anthropometric, MRI, and metabolic variables

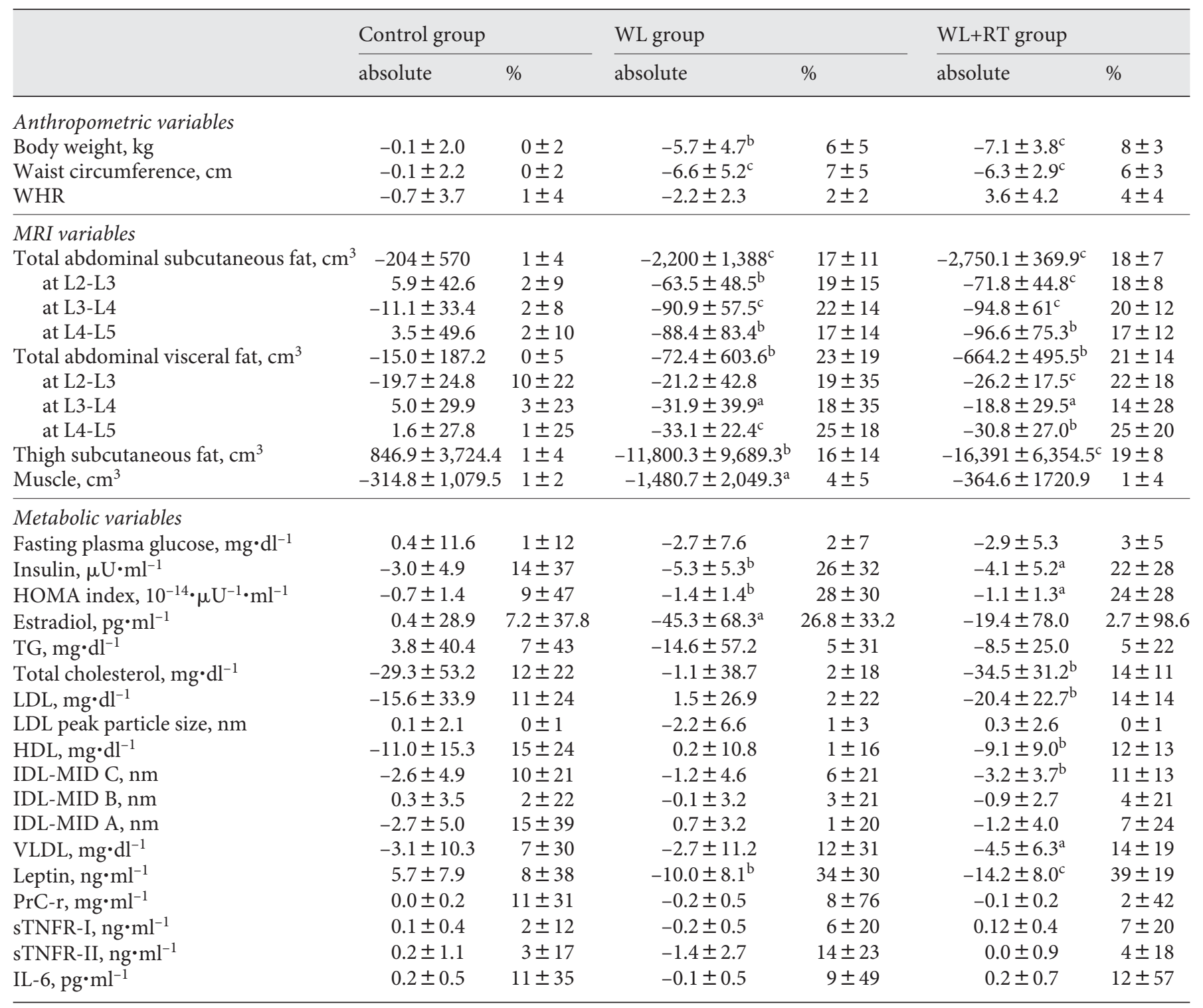

Values are expressed as means $\pm \mathrm{SD} .{ }^{\mathrm{a}} \mathrm{p}<0.05,{ }^{\mathrm{b}} \mathrm{p}<0.01,{ }^{\mathrm{c}} \mathrm{p}<0.001$, significant within-group changes between values in weeks 0 and 16 .

\section{Biological Variables}

Resting blood samples were drawn at weeks 0 and 16 . Venous blood samples were obtained at rest between 8:00 and 9:00 a.m. from the antecubital vein. Blood was drawn after $12 \mathrm{~h}$ of fasting and 1 day of minimal physical activity. The postintervention (week 16) blood drawing occurred 72-96 h after the last exercise session. Basal glycemia was analyzed using an enzymatic hexokinase method (Roche Diagnostics, Mannheim, Germany). Serum insulin levels were measured in duplicate by monoclonal immunoradiometric assay (INSI-CTK Irma; DiaSorin, Madrid, Spain). Intra- and inter-assay CV were $<5 \%$. Serum levels of estradiol and progesterone were radioimmunologically measured using commercial kits (Immunotech SAS, Marseille, France). The intra- and inter-assay accuracies were $6.2-9.5 \%$ and $6.6-10.2 \%$ of the CV for estradiol and $3.5-5.8 \%$ and $5.1-9.0 \%$ of the CV for progesterone. Serum leptin levels were measured by ELISA kits (LINCO Research, St. Charles, Mo., USA). The intra- and inter-assay CV were $<7 \%$. Serum C-reactive protein was determined by immunoturbidimetric assay (Beckman Coulter, Brea, Calif., USA), with intra- and inter-assay $\mathrm{CV}<4 \%$. Serum soluble TNF receptor 2 (sTNF-RII) and soluble TNF receptor 1 (sTNF-RI) concentration was measured using an sTNF-RII ELISA kit and an sTNF-RI ELI- 
SA kit (ARCUS Biologicals, Modena, Italy). Intra- and inter-assay CV for all of these determinations were 2.9 and $9.2 \%$, respectively, for sTNF-RII ELISA and 4.1 and 6.6\%, respectively, for sTNFRI ELISA. Serum IL- 6 concentrations were measured using a solid-phase, enzyme-labeled immunometric assay kit (Bender MedSystems GmbH, Vienna, Austria). The overall intra-assay CV has been calculated to be $6.9 \%$. The intra-assay and inter-assay CV were $8.0 \%$. Serum triglycerides (TG) were measured using Infinity Triglycerides Liquid Stable reagent (ThermoElectron, Noble Park, Vic., Australia). HDL cholesterol concentration was analyzed by a homogeneous method (ITC Diagnostics, Barcelona, Spain). The total cholesterol concentration was determined in serum according to the IL test cholesterol Trinder's method 18161810 (Instrumentations Laboratory Company, Lexington, Mass., USA). Lipoprotein particle size, LDL cholesterol, bands of intermediate density lipoprotein (IDL) cholesterol and VLDL cholesterol were determined using nongradient polyacrylamide gel electrophoresis (Lipoprint LDL System; Quantimetrix Inc., Redondo Beach, Calif., USA). The intra- and inter-assay CV were $<2 \%$.

\section{Energy Intake and Energy Expenditure Analysis}

At weeks 0 and 16 all subjects were interviewed by an experienced dietitian and given instructions on how to complete food records accurately. Three-day dietary food records (including 1 weekend day) were completed, with the records being filled out on the actual day of consumption of the foods. All food records were analyzed by DIETSOURCE (DietSource program, version 1.0; Novartis, Barcelona, Spain).

Similarly, habitual physical activity was evaluated by accelerometry (TriTrac-R3D System, software version 2.04; Madison, Wisc., USA). The TriTrac-R3D was worn on a belt that was firmly attached to the anterior torso of the subject at the level of the waist. TriTrac monitoring was recorded on a minute-by-minute basis over 2 weekdays and 2 weekend days, coinciding with the days of dietary food records.

\section{Hypocaloric Diet}

Each subject in the WL and WL+RT groups received a varied and well-balanced hypocaloric diet (55\% of calories as carbohydrates, $15 \%$ as proteins, and the rest as fat) of $500 \mathrm{kcal} / \mathrm{day}$, according to the previous analysis of individual daily energy expenditure by accelerometry. This diet was designed to elicit a $0.5 \mathrm{~kg}$ weight loss per week. The control group was asked to maintain their body weight. Throughout the 16-week intervention period, body weight was recorded once every 2 weeks in the WL and $\mathrm{WL}+\mathrm{RT}$ groups. Also, every 2 weeks each subject of the intervention groups participated in a series of 1-hour seminars in which the dietitian taught proper food selection and preparation, eating behavior, control of portion sizes, and modification of binge eating and other adverse habits.

\section{Strength Testing and Training Protocol}

Lower and upper body maximal strength was assessed using one repetition concentric maximum (1-RM) action in a half squat and in a bench press position, respectively. A detailed description of the 1-RM testing procedure can be found elsewhere [19]. Maximal strength variables showed reliability coefficients ranging from 0.80 to 0.99 , and the CV ranged from 2 to $7 \%$.

The strength training program used in the present study was similar to that reported previously [19]. Briefly, the subjects were asked to report to the training facility twice a week to perform dynamic resistance exercise for 45-60 min per session. A minimum of 2 days elapsed between two consecutive training sessions. Each training session included 2 exercises for the leg extensor muscles, 1 exercise for the arm extensor muscle and 4-5 exercises for the main muscle groups of the body. Only resistance machines (Technogym, Gambettola, Italy) were used throughout the training period. Resistance in this study was progressively increased or decreased every week for the 16-week training period using a repetition maximum approach.

During the first 8 weeks of the training period the subjects trained with loads of $50-70 \%$ of the individual 1-RM, and during the last 8 weeks of the training period the loads were $70-80 \%$ of the maximum. In addition, from week 8 to week 16 the subjects performed a part $(20 \%)$ of the leg extensor and bench press sets with loads ranging from 30 to $50 \%$ of the maximum. In all of the individual exercise sessions performed, one of the researchers was present to direct and assist each subject towards performing the appropriate work rates and loads. In all subjects average compliance with the diet classes and exercise sessions was above $95 \%$.

\section{Statistical Analysis}

Standard statistical methods were used for calculation of the means, standard deviation (SD), and Pearson's product-moment correlation coefficient. One-way analysis of variance (ANOVA) was used to determine any differences among the three groups' initial measurements. The resistance training- and/or diet-related effects were assessed using a two-way ANOVA with repeated measures (groups $\times$ time). When a significant $F$ value was achieved, Bonferroni's post hoc procedures were performed to locate the pairwise differences between the means. Selected relative changes were analyzed via one-way ANOVA. Analyses of covariance (ANCOVA) were used to adjust postinterventional values to compare the data between the groups. For this purpose, preinterventional values were used as covariates so that the effects of the covariance could be observed. $\mathrm{p}<0.05$ was considered statistically significant.

\section{Results}

\section{Subjects' Characteristics}

Baseline characteristics were similar in the 3 groups (table 1). After 16 weeks, no significant changes were observed in the different parameters evaluated in the control group. In turn, body mass, waist circumference, and the WHR were significantly diminished after 16 weeks of intervention in the WL and WL+RT groups $(\mathrm{p}<0.01$ and $\mathrm{p}<0.001$, respectively). No significant differences were observed in these anthropometric variables in either intervention group (table 2).

\section{Abdominal and Thigh Adipose Tissue Distribution after $W L$ and $W L+R T$ Interventions}

Total visceral and subcutaneous abdominal and subcutaneous thigh adipose tissue depots were significantly diminished after 16 weeks of intervention in the WL and 
Table 3. Partial correlation coefficients between some glucose metabolism variables and VAT and SAT discal levels

\begin{tabular}{|c|c|c|c|c|c|}
\hline & & $\begin{array}{l}\text { Basal } \\
\text { glycemia }\end{array}$ & Insulin & $\begin{array}{l}\text { HOMA } \\
\text { index }\end{array}$ & Leptin \\
\hline \multicolumn{6}{|c|}{ Preintervention } \\
\hline \multirow[t]{3}{*}{ SAT } & L2-L3 & $0.39^{\mathrm{a}}$ & $0.43^{\mathrm{a}}$ & $0.49^{\mathrm{a}}$ & $0.60^{c}$ \\
\hline & L3-L4 & $0.36^{\mathrm{a}}$ & 0.35 & $0.39^{a}$ & $0.70^{c}$ \\
\hline & L4-L5 & 0.25 & 0.27 & 0.27 & $0.71^{\mathrm{c}}$ \\
\hline \multirow[t]{3}{*}{ VAT } & L2-L3 & 0.26 & 0.35 & $0.40^{\mathrm{a}}$ & $0.40^{\mathrm{a}}$ \\
\hline & L3-L4 & 0.33 & $0.41^{\mathrm{a}}$ & $0.47^{\mathrm{b}}$ & 0.23 \\
\hline & L4-L5 & $0.39^{\mathrm{a}}$ & $0.60^{c}$ & $0.63^{c}$ & 0.26 \\
\hline \multicolumn{6}{|c|}{ Postintervention (only diet) } \\
\hline \multirow[t]{3}{*}{ SAT } & L2-L3 & 0.30 & 0.32 & 0.32 & $0.73^{\mathrm{b}}$ \\
\hline & L3-L4 & 0.45 & 0.34 & 0.37 & $0.86^{\mathrm{c}}$ \\
\hline & L4-L5 & 0.45 & 0.38 & 0.41 & $0.85^{\mathrm{c}}$ \\
\hline \multirow[t]{3}{*}{ VAT } & L2-L3 & 0.34 & $0.59^{\mathrm{a}}$ & $0.59^{\mathrm{a}}$ & $0.73^{\mathrm{b}}$ \\
\hline & L3-L4 & 0.47 & 0.48 & 0.51 & $0.82^{\mathrm{b}}$ \\
\hline & L4-L5 & 0.37 & 0.55 & 0.56 & $0.62^{\mathrm{a}}$ \\
\hline \multicolumn{6}{|c|}{ Postintervention $(\operatorname{diet}+\mathrm{RT})$} \\
\hline \multirow[t]{3}{*}{ SAT } & L2-L3 & 0.60 & $0.86^{\mathrm{b}}$ & $0.86^{\mathrm{b}}$ & $0.81^{\mathrm{b}}$ \\
\hline & L3-L4 & 0.53 & $0.72^{\mathrm{b}}$ & $0.73^{\mathrm{b}}$ & $0.74^{\mathrm{b}}$ \\
\hline & L4-L5 & $0.63^{\mathrm{a}}$ & $0.64^{\mathrm{a}}$ & $0.69^{\mathrm{a}}$ & $0.67^{\mathrm{a}}$ \\
\hline \multirow[t]{3}{*}{ VAT } & L2-L3 & 0.28 & 0.36 & 0.33 & 0.30 \\
\hline & L3-L4 & 0.48 & 0.52 & 0.51 & 0.39 \\
\hline & L4-L5 & 0.24 & 0.34 & 0.37 & 0.57 \\
\hline
\end{tabular}

Significant correlation: ${ }^{\mathrm{a}} \mathrm{p}<0.05,{ }^{\mathrm{b}} \mathrm{p}<0.01,{ }^{\mathrm{c}} \mathrm{p}<0.001$.

$\mathrm{WL}+\mathrm{RT}$ groups ( $\mathrm{p}<0.01$ and $\mathrm{p}<0.001$, respectively) (table 2). However, after intervention, no significant differences were observed in the magnitude of the decrease between the WL and WL+RT groups in the total VAT $(22.6$ and $20.9 \%$ ) and SAT (16.5 and 18.1\%) volumes, respectively (table 2).

After intervention, VAT and SAT volumes significantly decreased at all discal levels analyzed $(\mathrm{p}<0.05)$. No significant differences were observed in the magnitude of the decrease in VAT and SAT areas at the L2-L3 (16 and $19 \%$ vs. 18 and $18 \%$ ), L3-L4 (21 and 15\% vs. 21 and 20\%), and L4-L5 (22 and 26\% vs. 17 and 17\%) discal levels in $\mathrm{WL}$ and WL+RT, respectively. Finally, as expected, a significant loss of thigh muscle mass was observed in the WL group (5\%; $\mathrm{p}<0.05)$; however, the thigh muscle mass was maintained in the WL+RT group (table 2).

\section{Basal Relationships between MRI Variables and \\ Metabolic Variables, Lipid Profile, and \\ Adipocytokine Levels}

At baseline $(\mathrm{n}=34)$, the highest correlations with baseline glycemia, insulin, HOMA index, total cholesterol, and LDL cholesterol were observed at the VAT L4-L5 discal level (from $r=0.39$ to $r=0.63, p<0.05$ ). SAT L4-L5 presented a marked association with leptin $(\mathrm{r}=0.71, \mathrm{p}<$ 0.001 ) (table 3). Nevertheless, the glucose metabolism and lipid profile also presented significant correlations with the L2-L3 discal level ( $\mathrm{p}<0.05$ and $\mathrm{p}<0.01$, respectively) (tables 3, 4).

PrC-r, sTNF-RI, and sTNF-RII were correlated with VAT L3-L4 (range from $r=0.35$ to $r=0.42, p<0.05$ ), whereas IL-6 presented a marked correlation with the VAT/SAT L3-L4 discal level $(\mathrm{r}=0.51, \mathrm{p}<0.01)$. With regard to total subcutaneous thigh adipose tissue, only correlations with basal leptin $(\mathrm{r}=0.46, \mathrm{p}<0.01)$ and IL-6 $(r=-0.53, p<0.05)$ were found.

\section{Relationship between MRI Variables and Metabolic}

Variables after 16 Weeks of Intervention

In the WL+RT group, significant associations were observed between VAT L4-L5 and total cholesterol, LDLcholesterol, and TG (range from $\mathrm{r}=0.58$ to $\mathrm{r}=0.64$, $\mathrm{p}<$ $0.05)$ (table 4). The highest relationship for baseline insulin, HOMA index, and leptin was observed with SAT L2$\mathrm{L} 3$ (range from $\mathrm{r}=0.81$ to $\mathrm{r}=0.86, \mathrm{p}<0.01$ ) and for $\mathrm{LDL}$ cholesterol with the VAT L2-L3 discal level $(\mathrm{r}=0.58, \mathrm{p}<$ 0.05) (table 3).

In the WL group, baseline insulin showed a marked association with VAT/SAT L2-L3 ( $\mathrm{r}=0.59, \mathrm{p}<0.05)$, whereas HDL cholesterol and VLDL presented high correlations with SAT L2-L3 $(\mathrm{r}=-0.58, \mathrm{p}<0.05)$ and VAT/ SAT L2-L3 discal levels $(r=0.79, \mathrm{p}<0.01)$, respectively. Total cholesterol, TG, and IDL cholesterol subfraction B showed the highest correlations with VAT/SAT L4-L5 (range from $r=0.58$ to $r=0.73 ; p<0.05$ ), whereas leptin and IDL cholesterol subfraction $\mathrm{C}$ presented a marked association with the SAT L4-L5 discal level $(\mathrm{r}=0.85, \mathrm{p}<$ 0.001 and $r=-0.67, p<0.05$ ).

Finally, after 16 weeks of intervention, no correlation was observed between total subcutaneous thigh adipose tissue and any of these metabolic and lipid profile variables or baseline cytokines levels in either the WL group or the WL+RT group.

\section{Discussion}

The main findings of this study were that VAT L4-L5 was the area more closely associated with deterioration in many components of the cardiometabolic risk profile in adult obese women, and that after 16 weeks of intervention the association pattern between abdominal adipose 
tissue depots and glucose metabolism variables showed an evident change from the L4-L5 region to L2-L3 landmarks in both the WL group and the WL+RT group.

L4-L5 is the most commonly used landmark for measuring abdominal VAT and SAT. Recently we published that in the obese women of the present study VAT L4-L5 showed a marked correlation with total VAT $(r=0.84$, $\mathrm{p}=0.001$ ) [18]. However, some authors believe that L4-L5 is not the ideal site for quantifying abdominal adipose tissue or for predicting obesity-related cardiometabolic risk due to variations in the measurement method for quantifying abdominal adipose tissue. Recent studies report that a single image in the upper abdomen (i.e. at L2L3) is a more suitable surrogate for total VAT $[12,13]$ than an image at L4-L5. Nevertheless, in our study the VAT L2-L3 image showed a much weaker association with cardiometabolic risk factors than VAT L4-L5. By contrast, whereas the association between VAT and cardiovascular and metabolic risk is well established [3,20,21], the role played by SAT is less clear. In this context, Ross et al. [22] found a strong positive correlation between visceral fat and insulin resistance and no association between subcutaneous fat and insulin resistance in obese premenopausal women. In our study we found that abdominal VAT confers a greater cardiometabolic risk in obese premenopausal women than does abdominal SAT, in agreement with other studies $[3,23]$. SAT L2-L3 showed a weaker association with different variables of glucose metabolism. Of note, in our subjects the accumulation of fat in the midthigh depot was not characterized by a more favorable lipid profile or glucose metabolism. Therefore, taking these results as a whole, we may conclude that measurement of a single image at L4-L5 may be a suitable and accurate method to determine the cardiovascular and metabolic risk profile in obese adult women.

A novel finding of this study is that after 16 weeks of intervention the association pattern between abdominal adipose tissue depots and glucose metabolism variables showed an evident change from the L4-L5 region to L2L3 landmarks in both the WL group and the WL+RT group. Furthermore, although a similar improvement in insulin sensitivity (i.e. measured by the HOMA index), body mass reduction, and percent fat loss was observed in the WL and WL+RT groups (table 2), a unique finding was that glucose metabolism in the WL group only presented a marked association with VAT L2-L3, whereas in $\mathrm{WL}+\mathrm{RT}$ group these variables showed the highest correlation with SAT at the L2-L3 discal level (table 3). The rationale that explains these differences between interventional groups is unclear. Visceral adiposity has been as-
Table 4. Partial correlation coefficients between some glucose metabolism variables and VAT and SAT discal levels

\begin{tabular}{|c|c|c|c|c|c|c|}
\hline & & TG & TC & LDL-C & HDL-C & VLDL \\
\hline \multicolumn{7}{|c|}{ Preintervention } \\
\hline \multirow[t]{3}{*}{ SAT } & L2-L3 & -0.05 & 0.01 & 0.03 & -0.12 & 0.08 \\
\hline & L3-L4 & -0.05 & -0.07 & -0.04 & -0.03 & -0.10 \\
\hline & L4-L5 & -0.11 & -0.22 & -0.18 & -0.03 & -0.25 \\
\hline \multirow[t]{3}{*}{ VAT } & $\mathrm{L} 2-\mathrm{L} 3$ & 0.11 & $0.54^{\mathrm{b}}$ & $0.58^{\mathrm{b}}$ & 0.09 & 0.23 \\
\hline & L3-L4 & 0.18 & $0.39^{\mathrm{a}}$ & $0.46^{\mathrm{b}}$ & -0.04 & 0.18 \\
\hline & L4-L5 & 0.35 & $0.52^{\mathrm{b}}$ & $0.58^{\mathrm{b}}$ & 0.07 & 0.20 \\
\hline \multirow[t]{3}{*}{ VAT/SAT } & $\mathrm{L} 2-\mathrm{L} 3$ & 0.11 & $0.51^{\mathrm{b}}$ & $0.51^{\mathrm{b}}$ & 0.18 & 0.22 \\
\hline & L3-L4 & 0.20 & $0.39^{\mathrm{a}}$ & 0.42 & -0.02 & 0.27 \\
\hline & L4-L5 & 0.37 & $0.54^{\mathrm{b}}$ & $0.55^{\mathrm{b}}$ & 0.11 & 0.30 \\
\hline \multicolumn{7}{|c|}{ Postintervention (only diet) } \\
\hline \multirow[t]{3}{*}{ SAT } & L2-L3 & -0.01 & -0.41 & -0.32 & $-0.58^{\mathrm{a}}$ & -0.15 \\
\hline & L3-L4 & 0.06 & -0.38 & -0.34 & -0.47 & -0.17 \\
\hline & L4-L5 & 0.00 & -0.49 & -0.46 & -0.54 & -0.22 \\
\hline \multirow[t]{3}{*}{ VAT } & L2-L3 & 0.53 & 0.21 & 0.08 & 0.07 & 0.51 \\
\hline & L3-L4 & 0.41 & 0.01 & -0.12 & -0.13 & 0.40 \\
\hline & L4-L5 & 0.55 & 0.25 & 0.25 & -0.02 & 0.45 \\
\hline \multirow[t]{3}{*}{ VAT/SAT } & L2-L3 & $0.71^{b}$ & 0.52 & 0.25 & 0.48 & $0.79^{\mathrm{b}}$ \\
\hline & L3-L4 & $0.63^{\mathrm{a}}$ & 0.40 & 0.13 & 0.30 & $0.81^{\mathrm{b}}$ \\
\hline & L4-L5 & $0.73^{b}$ & $0.58^{\mathrm{a}}$ & 0.49 & 0.33 & $0.74^{\mathrm{a}}$ \\
\hline \multicolumn{7}{|c|}{ Postintervention (diet+PRT) } \\
\hline \multirow[t]{3}{*}{ SAT } & $\mathrm{L} 2-\mathrm{L} 3$ & 0.30 & 0.41 & 0.32 & 0.27 & 0.43 \\
\hline & L3-L4 & 0.27 & 0.42 & 0.29 & 0.39 & 0.37 \\
\hline & L4-L5 & 0.20 & 0.19 & 0.07 & 0.24 & 0.30 \\
\hline \multirow[t]{3}{*}{ VAT } & L2-L3 & 0.43 & 0.53 & 0.50 & 0.06 & 0.41 \\
\hline & L3-L4 & 0.36 & 0.51 & 0.52 & 0.15 & 0.38 \\
\hline & L4-L5 & $0.64^{\mathrm{a}}$ & $0.60^{\mathrm{a}}$ & $0.58^{\mathrm{a}}$ & 0.54 & 0.30 \\
\hline \multirow[t]{3}{*}{ VAT/SAT } & L2-L3 & 0.39 & 0.35 & 0.44 & -0.10 & 0.30 \\
\hline & L3-L4 & 0.33 & 0.27 & 0.35 & -0.12 & 0.25 \\
\hline & L4-L5 & $0.59^{a}$ & 0.48 & 0.45 & 0.38 & 0.15 \\
\hline
\end{tabular}

Significant correlation: ${ }^{\mathrm{a}} \mathrm{p}<0.05,{ }^{\mathrm{b}} \mathrm{p}<0.01$.

sociated with insulin resistance and glucose intolerance [24-26]. The liver has specifically been implicated as a primary site of insulin resistance observed with visceral obesity. The mechanisms relating visceral fat accumulation and hepatic insulin resistance are not well known, but several possible factors might be implicated. One hypothesis states that cytokines secreted by visceral fat such as IL-6 and TNF may explain the metabolic complications associated with visceral obesity [27]. Indeed, these adipose tissue-derived cytokines are strongly associated with insulin resistance [27], and the secretion of IL- 6 is greater in visceral than abdominal subcutaneous adipocytes [28]. However, in the present study no association was found between cytokines, $\mathrm{PrC}-\mathrm{r}$ and circulating insulin levels or insulin sensitivity before or after interven- 
tion either during 16 weeks of a PRT program and/or a weight-loss diet. The alternative 'portal hypothesis' posits a high rate of lipolysis of VAT leading to increased delivery of free fatty acids to the liver via the portal vein, thus contributing to increased fat accumulation and liver insulin resistance [29-31]. Consistent with the portal hypothesis, several studies have shown that FFA turnover and lipolysis are higher in visceral than in subcutaneous fat and that the visceral adipose depot is less sensitive to the antilipolytic effect of insulin [32].

Regarding the strength of the association between abdominal SAT L2-L3 and glucose metabolism in the $\mathrm{WL}+\mathrm{RT}$ group, one could speculate about the physiological significance of this change in associations between abdominal adipose tissue depots and glucose metabolism. It has been suggested that abdominal SAT may also play an important role as an independent marker of insulin resistance in obesity [33]. However, it is unclear why the addition of a PRT program to a weight-loss diet would influence the strength of the association between SAT and glucose metabolism variables but not VAT and glucose metabolism. One reason may be the marked relation observed after 16 weeks of a weight-loss diet and PRT between basal circulating leptin and insulin levels $(\mathrm{r}=0.82$, $\mathrm{p}=0.001)$ and the HOMA value $(\mathrm{r}=0.80, \mathrm{p}=0.001)$, whereas no association between leptin and glucose metabolism was observed in the WL group. In agreement with our findings, a previous study by Ryan [14] concluded that after 16 weeks of a WL+RT program in obese postmenopausal women the increase in insulin action may have been related to the decrease in leptin levels that were mediated by the loss of body fat. It is known that leptin regulates insulin sensitivity and glucose homeostasis via two different pathways: one through an adiposity-dependent mechanism, by controlling energy balance and body fat (increased body adiposity leads to insulin resistance), and the other through an adiposity-independent pathway mediated by the CNS $[34,35]$.

Finally, in a previous study we reported that after 16 weeks of a weight-loss diet intervention no significant changes were observed in the lipid profile of the hypercholesterolemic obese women of the present study, whereas the $\mathrm{WL}+\mathrm{RT}$ group experienced a significant decrease in TC and LDL-C [17] (table 2). It is generally recognized that visceral adiposity is associated with dyslipidemia [24] and visceral fat loss with an improvement of the serum lipid profile in women [36, 37]. Accordingly, in the present study the improvement in lipid profile in the $\mathrm{WL}+\mathrm{RT}$ group presented a marked association with VAT L4-L5. Of note, no correlation was observed between midthigh SAT and lipid profile or glucose metabolism variables in either the WL+RT group or the WL group. The thigh adipose tissue depot has been postulated to actually play a protective role against cardiovascular disease and type 2 diabetes mellitus in women [21]. In a previous study, Janssen and Ross [38] found a preferential reduction of abdominal versus thigh SAT in response to diet and resistance training, but not diet alone, in premenopausal women. Indeed, it seems that abdominal subcutaneous adipocytes are more sensitive to catecholamine stimulation during exercise than lower body adipocytes [39]. The fact that the abdominal subcutaneous fat depot is preferentially reduced in response to diet and exercise may convey a health risk benefit as abdominal SAT is an independent predictor of metabolic risk factors in both sexes [33]. In our study comparisons of average changes in abdominal and thigh subcutaneous fat mass showed a similar adipose tissue loss pattern in both the $\mathrm{WL}$ group and the WL+RT group (table 2). The rationale that explains these results is unknown and warrants further investigation.

In conclusion, although we assume that the inclusion of women in different phases of menopause in the same group is a limitation, the results of our study reinforce the importance of considering VAT L4-L5 as a critical correlate of the cardiovascular and metabolic risk profile in obese women. Furthermore, both VAT L2-L3 and SAT L2-L3 are independent predictors of insulin resistance, whereas VAT L4-L5 is a predictor of the lipid profile, after a weight-loss diet alone or combined with a PRT program. Finally, although the mechanisms for these distinct adaptations of abdominal visceral and subcutaneous adiposity in association with cardiovascular and metabolic risk factors remain to be further determined, these findings provide support for the concept that fat located at midthigh levels does not seem to protect perimenopausal women against deteriorations in the cardiometabolic risk profile.

\section{Acknowledgments}

The study was supported by grant No. 04/1594 from the Instituto de Salud Carlos III, Ministerio de Sanidad y Consumo, Spain.

\section{Disclosure Statement}

None of the authors has a personal or financial conflict of interest.

Ann Nutr Metab 2012;61:296-304 


\section{References}

1 World Health Organization: Preventing chronic diseases: a vital investment. Geneva, WHO, 2005.

2 World Heart Federation: September, 2009. http://www.world-heart-federation.org/ what-we-do/go-red-for-women/get-thefacts/.

$\checkmark 3$ Williams MJ, Hunter GR, Kekes-Szabo T, Snyder S, Treuth MS: Regional fat distribution in women and risk of cardiovascular disease. Am J Clin Nutr 1997;65:855-860.

$\checkmark 4$ Hunter GR, Kekes-Szabo T, Snyder SW, Nicholson C, Nyikos I, Berland L: Fat distribution, physical activity, and cardiovascular risk factors. Med Sci Sports Exerc 1997;29: 362-369.

5 Gnacińska M, Małgorzewicz S, Stojek M, Lysiak-Szydłowska W, Sworczak K: Role of adipokines in complications related to obesity: a review. Adv Med Sci 2009;29:1-8.

-6 Dobbelsteyn CJ, Joffres MR, MacLean DR, Flowerdew G: A comparative evaluation of waist circumference, waist-to-hip ratio and body mass index as indicators of cardiovascular risk factors: the Canadian Heart Health Surveys. Int J Obes Relat Metab Disord 2001; 25:652-661.

7 Okosun IS, Liao Y, Rotimi CN, Prewitt TE, Cooper RS: Abdominal adiposity and clustering of multiple metabolic syndrome in Black and Hispanic population. Ann Epidemiol 2000;10:263-270.

$>8$ Haffner SM, Stern MP, Hazuda HP, Pugh J, Patterson JK, Malina R: Upper body and centralized obesity in Mexican American and non-Hispanic whites: relationship to body mass index and other behavioral and demographic variables. Int J Obes 1986;10:493502

$>9$ Haffner SM, Stern M, Hazuda HP, Pugh J, Patterson JK: Do upper-body and centralized adiposity measure different aspects of regional body-fat distribution? Relationships to non-insulin-dependent diabetes mellitus, lipids and lipoproteins. Diabetes 1987;36:43-51

$>10$ Ross R, Kimberley DS, Martel Y, De Guise J, Avruch L: Adipose tissue distribution measured by magnetic resonance imaging in obese women. Am J Clin Nutr 1993;57:470-475.

$>11$ Staten MA, Totty WG, Kohrt WM: Measurement of fat distribution by magnetic resonance imaging. Invest Radiol 1989;24:345349.

$\checkmark 12$ Kuk JI, Church TS, Blair SN, Ross R: Does measurement site for visceral and abdominal subcutaneous adipose tissue alter associations with the metabolic syndrome? Diabetes Care 2006;29:679-684.

$\checkmark 13$ Demerath EW, Shen W, Lee M, Choh AC, Czerwinski SA, Siervogel RM, Towne B: Approximation of total visceral adipose tissue with a single magnetic resonance image. Am J Clin Nutr 2007;85:362-368.
14 Ryan AS: Insulin resistance with aging: effects of diet and exercise. Sports Med 2000; 30:327-346.

15 Ibáñez J, Izquierdo M, Argüelles I, Forga L, Larrión JL, García-Unciti M, Idoate F, Gorostiaga EM: Twice-weekly progressive resistance training decreases abdominal fat and improves insulin sensitivity in type 2 diabetic mellitus older men. Diabetes Care 2005;28:662-667.

16 Treuth MS, Hunter GR, Kekes-Szabo T, Weinsier RL, Goran MI, Berland L: Reduction in intra-abdominal adipose tissue after strength training in older women. J Appl Physiol 1995;78:1425-1431.

17 Ibáñez J, Izquierdo M, Martínez-Labari C, Ortega F, Grijalba A, Forga L, Idoate F, García-Unciti M, Fernández-Real JM, Gorostiaga EM: Resistance training improves cardiovascular risk factors in obese women despite a significative decrease in serum adiponectin levels. Obesity 2010;18:535-541.

18 Idoate F, Ibañez J, Gorostiaga EM, GarcíaUnciti M, Martínez-Labari C, Izquierdo M Weight-loss diet alone or combined with resistance training induces different regional visceral fat changes in obese women. Int Obes (Lond) 2011;35:700-713.

19 Izquierdo M, Häkkinen K, Ibañez J, Garrués M, Antón A, Zúñiga A, Larrión JL, Gorostiaga EM: Effects of strength training on muscle power and serum hormones in middle-aged and older men. J Appl Physiol 2001;90:14971407.

20 Després JP: Is visceral obesity the cause of the metabolic syndrome? Ann Med 2006;38: 52-63.

21 Piché M-E, Lapointe A, Weisnagel SJ, Corneau L, Nadeau A, Bergeron J, Lemieux S: Regional body fat distribution and metabolic profile in postmenopausal women. Metab olism 2008;57:1101-1107.

22 Ross R, Freeman J, Hudson R, Janssen I: Abdominal obesity, muscle composition, and insulin resistance in premenopausal women. J Clin Endocrinol Metab 2002;87:50445051.

23 Després JP, Nadeau A, Tremblay A, Ferland M, Moorjani S, Lupien PJ, Thériault G, Pinault S, Bouchard C: Role of deep abdominal fat in the association between regional adipose tissue distribution and glucose tolerante in obese women. Diabetes 1989;38:304309.

24 DeFronzo RA, Ferrannini E: Insulin resistance: a multifaceted syndrome responsible for NIDDM, obesity, hypertension, dyslipidemia, and atherosclerotic cardiovascular disease. Diabetes Care 1991;14:173-194.

25 Evans DJ, Hoffmann RG, Kalkhoff RK, Kissebah AH: Relationship of body fat topography to insulin sensitivity and metabolic profiles in premenopausal women. Metabolism 1984;33:68-75.
26 Golay A, Chen N, Chen YD, Hollenbeck C, Reaven GM: Effect of central obesity on regulation of carbohydrate metabolism in obese patients with varying degrees of glucose tolerance. J Clin Endocrinol Metab 1990;71: 1299-1304.

27 Kern PA, Ranganathan S, Li C, Wood L, Ranganathan G: Adipose tissue tumor necrosis factor and interleukin-6 expression in human obesity and insulin resistance Am J Physiol Endocrinol Metab 2001;280:E745-E751.

28 Fried SK, Bunkin DA, Greenberg AS: Omental and subcutaneous adipose tissues of obese subjects release interleukin-6: depot difference and regulation by glucocorticoid. J Clin Endocrinol Metab 1998;83:847-850.

29 Bergman RN, Ader M: Free fatty acids and pathogenesis of type 2 diabetes mellitus. Trends Endocrinol Metab 2000;11:351-356.

-30 Bjorntorp P: 'Portal' adipose tissue as a generator of risk factors for cardiovascular disease and diabetes. Arteriosclerosis 1990;10: 493-496.

31 Boden G: Role of fatty acids in the pathogenesis of insulin resistance and NIDDM. Diabetes 1997;46:3-10.

32 Ostman J, Arner P, Engfeldt P, Kager L: Regional differences in the control of lipolysis in human adipose tissue. Metabolism 1979; 28:1198-1205.

33 Goodpaster BH, Thaete FL, Simoneau JA, Kelly DE: Subcutaneous abdominal fat and thigh muscle composition predict insulin sensitivity independently of visceral fat. Diabetes 1997;46:1579-1585.

34 Pittas AG, Joseph NA, Greenberg AS: Adipocytokines and insulin resistance. J Clin Endocrinol Metab 2004;89:447-452.

35 Ahima RS, Qi Y, Singhal NS, Jackson MB, Scherer PE: Brain adipocytokine action and metabolic regulation. Diabetes 2006;55 (suppl 2):S145-S154.

36 Leenen R, van der Kooy K, Droop A, Seidell JC, Deurenberg P, Weststrate JA, Hautvast JG: Visceral fat loss measured by magnetic resonance imaging in relation to changes in serum lipid levels in obese men and women. Arterioscler Thromb 1993;13:487-494.

37 Després JP, Pouliot MC, Moorjani S, Nadeau A, Tremblay A, Lupien PJ, Thériault G, Bouchard C: Loss of abdominal fat and metabolic response to exercise training in obese women. Am J Physiol 1991;261:E159-E167.

38 Janssen I, Ross R: Effects of sex on the change in visceral subcutaneous adipose tissue and skeletal muscle in response to weight loss. Int J Obes 1999;23:1035-1046.

39 Jensen MD, Cryer PE, Johnson CM, Murry MJ: Effects of epinephrine on regional free fatty acid and energy metabolism in men and women. Am J Physiol 1996;270:E259-E264. 